\title{
Ciência e arte: investigações sobre identidades, diferenças e diálogos
}

Francisco Romão Ferreira

Instituto Oswaldo Cruz

\begin{abstract}
Resumo
Este artigo narra a construção da disciplina "Leituras e reflexões em Filosofia, Ciência e Arte", que faz parte de um projeto desenvolvido pelo Programa de Pós-graduação no Ensino de Ciências do Instituto Oswaldo Cruz/Fundação Oswaldo Cruz (10C/FlOCRUZ), ligado à linha de pesquisa "Ciência e Arte como estratégia de motivação para educação em ciência e saúde", cujo objetivo é desenvolver ferramentas pedagógicas que conciliem o uso da ciência e da arte no ensino das ciências da saúde. A proposta da disciplina é de tentar identificar os possíveis referenciais teóricos que permitam refletir acerca da interface entre essas duas áreas; identificar elementos que demonstrem o potencial desse diálogo para o processo de ensino-aprendizagem; valorizar a imaginação, a criatividade e a intuição; potencializar a capacidade criativa que viabilize uma "recriação do ensino"; produzir uma reflexão sistemática sobre a interação complexa do ensinar e aprender, do instruir e o compartilhar saberes; além de apontar para a perspectiva de pensar crítica e detalhadamente os processos artísticos e científicos. 0 objetivo central da disciplina é identificar e contrapor diferentes referenciais teóricos e refletir acerca dos padrões de interação entre a Educação, a Arte e a Ciência no campo da Saúde.
\end{abstract}

\section{Palavras-chave}

Arte - Filosofia - Ciência - Educação.

\section{Correspondência:}

Francisco Romão Ferreira

Rua Carmela Dutra, 05 apto 307

20250080 - Rio de Janeiro - RJ

E-mail: fromao@terra.com.br 


\title{
Science and art: investigations on identities, differences and dialogues
}

Francisco Romão Ferreira

Instituto Oswaldo Cruz

\begin{abstract}
This article details the construction of the discipline "Readings and reflections in Philosophy, Science and Art", which is part of a project developed by the Program of Graduate Studies in the Teaching of Sciences of the Oswaldo Cruz Institute/Oswaldo Cruz Foundation (1OC/FIOCRUZ), linked to the line of research entitled "Science and Art as a motivation strategy for education in science and health", whose objective is to create pedagogical tools to bring together science and art in the teaching of the health sciences. The discipline's proposal is to identify possible theoretical frameworks that might help to reflect about the interface between these two areas; to identify elements that demonstrate the potential of such dialogue for the teaching-learning process; to value imagination, creativity and intuition; to stimulate the creative drive to "re-create teaching"; to produce a systematic reflection about the complex interaction between teaching and learning, between instructing and sharing knowledges; and also to point toward the perspective of thinking critically and carefully about the artistic and scientific processes. The central aim of the discipline is to identify and contrast different theoretical frameworks, and to reflect upon the patterns of interaction between Education, Art and Science in the field of Health.
\end{abstract}

\section{Keywords}

Art - Philosophy - Science - Education. 
Este artigo narra a construção da disciplina "Leituras e reflexões em Filosofia, Ciência e Arte", que faz parte de um projeto mais amplo desenvolvido no 10C/FlOCRUZ e é ligado à linha de pesquisa "Ciência e Arte como estratégia de motivação para educação em ciência e saúde", cujo objetivo é desenvolver ferramentas pedagógicas que conciliem o uso da ciência e da arte $^{1}$ no ensino das ciências da saúde. 0 projeto é realizado pelos componentes do grupo Ciência, Arte, Saúde e Alegria (CASA), que é constituído por professores e alunos da pós-graduação que desenvolvem atividades de pesquisa, atuam na formação de profissionais do campo da Saúde, lidam com a interface arte e ciência e utilizam a arte e a criatividade como meios facilitadores para o trabalho interdisciplinar no campo das ciências da saúde. A disciplina é coordenada pelo Prof. Dr. Francisco Romão Ferreira e faz parte do trabalho de campo da sua pesquisa de pósdoutorado em curso.

Os participantes da pesquisa, assim como os alunos da disciplina, promovem a integração de diferentes estratégias de educação na formação de profissionais de saúde, atuando tanto em espaços tradicionais, como os espaços escolares (com professores do ensino fundamental e médio), como também na formação de profissionais de saúde e de alunos da graduação e pós-graduação. Os pesquisadores e estudantes dessa linha de pesquisa propõem a utilização de diferentes linguagens artísticas que possam sensibilizar professores e alunos para um ensino de ciências mais criativo, ampliando a percepção do papel da ciência e da arte; desenvolvendo estratégias, processos, metodologias e produtos que aumentem a criatividade na formação dos futuros cientistas ou profissionais de saúde; e ainda praticando um ensino que estimule a imaginação, a criatividade, a sensibilidade e a intuição.

\section{O significado da arte}

A ideia de que Arte e Ciência são campos opostos e inconciliáveis traduz um preconceito surgido no Período Moderno. Ao estudarmos o sistema das "artes liberais" da ldade Média, observamos que a primeira parte do ensino universitário era formada pelas três disciplinas do trivium (gramática latina, lógica e retórica), seguidas pelas disciplinas do quadrivium (aritmética, geometria, música e astronomia - o conjunto dos quatro ramos do saber). Juntas, elas constituíam as sete artes ou as artes liberais. Nesse periodo, o horizonte científico e o horizonte artístico se confundiam. A oposição entre arte e ciência está, portanto, inscrita na órbita de um tipo de pensamento que separou esses saberes e os manteve isolados em suas especialidades, como se não houvesse possibilidade de diálogo entre eles. Arte e ciência foram se afastando e, no paradigma dominante, elas passaram a assumir características, linguagens, métodos, processos cognitivos e vinculações epistemológicas independentes e diferenciadas e, às vezes, também opostas.

0 termo art que é utilizado na língua inglesa desde o século XIIl, vem da precursora imediata art, do francês antigo que, por sua vez, é originária da palavra artem, do latim, de cuja raiz deriva e cujo significado é "habilidade". Até o final do século XVIIl, o termo é utilizado em assuntos tão diversos como a habilidade na matemática, na medicina ou na pesca com vara. Segundo Willians (2007), até o século XVIII,

[...] a maioria das ciências eram artes; a distinção moderna entre ciência e arte, como áreas opostas de habilidade e de esforço humanos, com métodos e finalidades fundamentalmente diferentes, remonta a meados do século XIX, embora os próprios termos se tenham contraposto muito antes, no sentido de 'teoria' e 'prática'. (p. 60)

0 uso que damos hoje ao termo Arte, com letra maiúscula, ou ao adjetivo "artista", como pessoa imaginativa ou criativa, datam do final do século XVIIl e início do século XIX.

1. Sob a coordenação da Profa. Dra. Tânia Cremonini de Araújo Jorge. 
A palavra arte, que em sua origem latina ars significa habilidade, designa até o século $\mathrm{XV}$, no ocidente, apenas um conjunto de atividades ligadas à técnica, ao ofício, à perícia, isto é, a atividades essencialmente manuais.

Sua fundação, enquanto ciência, é o resultado de um longo processo de emancipação que, pelo menos no Ocidente, concerne ao conjunto da atividade espiritual, intelectual, filosófica e artística, sobretudo a partir da Renascença. (Jimenez, 1999, p. 32)

Nos séculos XVl e XVIl, enquanto a ciência se consolidava como forma de produção de conhecimento baseada nos princípios da razão, da lógica e do pensamento matemático, visando a uma interferência ativa e objetiva na natureza, as preocupações teóricas do campo da Arte vão incorporar a subjetividade, a discussão acerca da moralidade, da sensibilidade, da cultura como uma segunda natureza e da faculdade individual de julgamento do gosto.

A definição precisa do campo da Arte é uma tarefa inviável, pois o que é considerado arte ou artístico abarca diferentes dimensões temporais (desde a pré-história até o futuro da ficção científica); compreende todas as áreas habitadas da comunidade humana (independente do seu estágio tecnológico ou cultural); incorpora diversos tipos de manifestação (como as artes visuais, a dança, o teatro, o cinema, a jardinagem etc.); tanto se manifesta numa escala macro (incorporando monumentos e cidades, com suas ruas, praças, parques etc.), quanto numa escala micro (incorporando miniaturas, joias, objetos, roupas de época, moedas etc.); como também compreende as atividades técnicas (como a marcenaria, ourivesaria, construção civil etc.), atendendo a suas funções práticas, representativas e ornamentais. A polissemia do termo arte, da mesma forma, compreende diversos sentidos que vão desde a capacidade ou perícia para executar uma tarefa, capacidade criadora, até o conjunto de obras de uma época ou país, diferentes períodos, estilos ou escolas, diversos movimentos artísticos, diferentes obras ou objetos, ofícios, artifícios, artimanhas ou capacidades. Ou seja: é uma palavra aberta que incorpora uma multiplicidade de sentidos e modos de compreensão.

Segundo Argan (1994), o conceito de arte não define categorias de coisas, mas um tipo de valor. A arte está ligada ao trabalho humano e suas técnicas mentais e operacionais são formas significantes às quais a consciência atribui significados. Para ele, a história da arte não é uma história dos objetos, mas uma história dos juízos de valor acerca dos objetos e, por isso, ela é fundamental para compreender a sociedade. Ainda segundo Argan (1992), a arte é a busca de um sistema que dê conta de todas as relações possíveis, pois as técnicas artísticas são técnicas de ideação a partir de um fazer autônomo. Fazer arte é muito mais do que executar uma tarefa, pois requer uma dimensão reflexiva, uma fenomenologia da forma, uma percepção conformadora e formadora, que expande a percepção do mundo e produz uma reflexividade que pressupõe diferentes possibilidades de sentidos. Para ele, a construção da obra de arte é um processo cognoscitivo amplo, na medida em que "o melhor objeto que o homem pode produzir é aquele que contém uma experiência mais ampla, uma concepção total do mundo". Como também, "a obra de arte é o objeto único, que tem o máximo de qualidade e o mínimo de quantidade" (p. XVIII-XIX). A obra de arte, portanto, incorpora elementos sociais, históricos, cognoscitivos, éticos, religiosos ou formais, sem privilegiar qualquer uma das instâncias envolvidas. Nesse sentido, a arte se contrapõe à ciência, que busca a redução às leis universais, à padronização dos procedimentos metodológicos e o rigor lógico na construção dos saberes, na tentativa de controlar o que é do seu domínio. A obra de arte, ao contrário, continua produzindo significados independentemente do que foi imaginado pelo seu criador. Ela produz sensações e modos abstratos de pensamento que escapam aos domínios da racionalidade ou da lógica. 
A partir do século XVIIl, desde Kant (1724-1804) com a obra Crítica da faculdade de julgar, Schiller (1759-1805) com a publicação das Cartas para a educação estética do homem e Baumgarten (1714-1762) com o tratado Aesthetica, a arte passa a fazer parte da “esfera estética”, devendo ser julgada a partir de parâmetros de beleza, que colocam as obras de arte como objetos de fruição, contemplação e criação artística. Beleza e arte passam a se constituir em um todo único e inseparável (Carchia; D’Angelo, 1999). A arte incorpora a subjetividade e passa a se distanciar cada vez mais da Ciência, pois incorpora a sensação, a imaginação, o sentimento, o entusiasmo, o gosto pessoal, as paixões, a memória, ou seja, critérios que se afastam do ideal de clareza, objetividade e verdade - que são os pilares do pensamento científico.

A obra de arte traduz os conflitos históricos e os problemas políticos, morais ou epistêmicos do seu tempo. Para Argan (1994),

[...] a obra de um grande artista é uma realidade histórica que não fica atrás da reforma religiosa de Lutero, da política de Carlos $\mathrm{V}$, das descobertas científicas de Galileu. Ela é, pois, explicada historicamente, como se explicam historicamente os fatos da política, da economia, da ciência. (p. 17)

Existiria, portanto, uma relação entre os problemas artísticos e o desenvolvimento do conhecimento humano.

\section{O modelo científico}

A revolução científica iniciada no século XVl dá início a um processo social e a uma concepção de ciência que perdura até hoje. As relações sociais vão ser orientadas por uma racionalidade científica que tudo explica e resolve com seu discurso "neutro", racional e independente. Esse modelo de racionalidade se constituiu tendo como modelo as ciências naturais, especialmente a física, e
[...] sendo um modelo global, a nova racionalidade é também um modelo totalitário, na medida em que nega o caráter racional a todas as formas de conhecimento que não se pautarem pelos seus princípios epistemológicos e pelas suas regras metodológicas. (Santos, 2004, p. 21)

Desse modo, a arte, por não se pautar nos princípios de verdade e racionalidade objetiva da ciência nascente, passa a ocupar outro espaço na esfera do conhecimento.

0 modelo científico se constitui a partir de uma lógica matemática que se torna o instrumento privilegiado de análise, assim como a investigação e a representação da própria estrutura da matéria. Sendo assim, conhecer significa quantificar e representar a partir de um modelo construído, às vezes, arbitrariamente.

As qualidades intrínsecas do objeto são, por assim dizer, desqualificadas e em seu lugar passam a imperar as quantidades em que eventualmente se podem traduzir. 0 que não é quantificável é cientificamente irrelevante. Em segundo lugar, o método científico assenta na redução da complexidade. (Santos, 2004, p. 28)

A racionalidade científica moderna não se caracteriza por seu caráter contemplativo, ela se constitui como um saber que propõe uma intervenção na natureza com a intenção de dominá-la, transformá-la, agir sobre ela. Seus conceitos e pressupostos reproduzem uma concepção de mundo mecanicista, dualista, quantitativista e ordenadora. Ou seja: é um tipo de conhecimento que, ao interferir, modela, constrói a realidade, organiza segundo seus interesses, seus pressupostos e seus métodos, ela age no social, embora isso nem sempre fique explícito. Nessa racionalidade, a subjetividade é um problema a ser evitado.

Desde Descartes, conhecer implica desmembrar, classificar e eliminar o acidental, o aleatório, o subjetivo, considerando-se que 
aquilo que não pode ser medido, dividido, quantificado e organizado, dentro de uma lógica própria, não pode ser conhecido. Essa concepção, além de possuir uma base matemática, tem como referência um modelo mecanicista, funcional, que reduz tudo o que há no universo a relações mecânicas de causa e efeito. Esse método propicia a formulação de leis gerais que poderiam explicar e controlar a natureza e a vida, as regularidades observadas permitiriam estabelecer as leis que fundamentariam o comportamento de todos os fenômenos, naturais ou sociais.

Daí que o prestígio de Newton e das leis simples a que reduzia toda a complexidade da ordem cósmica tenham convertido a ciência moderna no modelo da racionalidade hegemônica que pouco a pouco se transbordou do estudo da natureza para o estudo da sociedade. (Santos, 2004, p. 32)

No entanto, esse paradigma, que nasceu com Descartes e Newton, já não consegue mais explicar a realidade em sua totalidade e complexidade. A hipótese de causalidade, implícita nesse paradigma, já não é mais suficiente nem necessária para dar conta das incertezas do real. Desde Kant, já sabemos que o real é incognoscivel e, desde Heisenberg e Bohr, já aprendemos que não é possível conhecer o real sem interferir nele, sem o alterar, e o próprio objeto do conhecimento se faz de acordo com o processo de conhecimento. Eles não são neutros, nem o objeto nem o processo, muito menos o sujeito. 0 que conhecemos do real se dá a partir da intervenção que operamos nele, a partir das condições de observação, dos critérios de análise ou da seleção do objeto. 0 olhar do observador vai interferir decisivamente no processo.

A crise desse paradigma dominante se faz sentir a partir de vários ângulos. 0 modelo de causalidade, finalidade e relação mecânica já não dá mais conta de conhecer a natureza e, menos ainda, a vida social. Simultaneamente, junto com a crise da ciência no século $X X$ acontece a percepção de que a autonomia da ciência, sua neutralidade e sua desvinculação dos problemas que afetam a vida social não são fatores irrelevantes, externos, alheios à realidade e desvinculados dos interesses e conflitos das questões políticas e econômicas.

Para Santos (2004), esse questionamento

[...] faz parte de um movimento convergente, pujante, sobretudo a partir da última década, que atravessa as várias ciências da natureza e até as ciências sociais, um movimento de vocação transdisciplinar que Jantsch designa por paradigma da auto-organização e que tem aflorações, entre outras, na teoria de Prigogine, na sinergética de Haken, no conceito de hiperciclo e na teoria da vida da Eigen, no conceito de autopoiesis de Maturana e Varela, na teoria das catástrofes de Thom, na teoria da evolução de Jantsch, na teoria da ordem implicada de David Bohm ou na teoria da matriz-S de Geoffrey Chew e na filosofia do "bootstrap" que lhe subjaz. Esse movimento científico e as demais inovações teóricas que atrás defini como outras tantas condições teóricas da crise do paradigma dominante têm vindo a proporcionar uma profunda reflexão epistemológica sobre o conhecimento científico, uma reflexão de tal modo rica e diversificada que, melhor do que qualquer outra circunstância, caracteriza exemplarmente a situação intelectual do tempo presente. (p. 48)

A crise do modelo científico hegemônico aponta seus limites e abre o caminho para novas perspectivas, entre elas, a busca por um diálogo com outros campos e uma maior permeabilidade em seus assuntos e métodos, mas sem perder o rigor que o caracteriza. A reflexão acerca da rigidez das ciências exatas, a relativização da produção do conhecimento que pode variar a partir da perspectiva do observador, a crescente influência das ciências humanas, a percepção da influência dos interesses externos à produção científica e a busca por novos métodos (mais flexíveis), permi- 
tem uma aproximação com outros campos do saber que antes sequer poderia ser cogitada. $\mathrm{Na}$ aproximação com a arte erudita, por exemplo, percebemos que inúmeros fatores são comuns aos dois campos, pois ambos utilizam imaginação, criatividade, intuição, construção de modelos abstratos, questionamento dos modelos vigentes, procedimentos rigorosos de pesquisa, busca por novas linguagens, extrema organização na construção dos trabalhos, procedimentos lógicos e processos cognitivos complementares, enfim, existem muitas semelhanças que podem ser exploradas e analisadas de modo a potencializar os dois campos.

A Arte, por sua vez, não se refere apenas ao belo e ao efêmero, embora possa representar objetos belos. A Arte é uma forma específica de produção de conhecimento. Ela não se reduz ao estético - não só porque não aspira exclusivamente à beleza e à fruição, mas também porque mantém uma série de ligações com âmbitos que ultrapassam o contexto estético com funções cognoscitivas e com funções práticas. A dimensão artística pode ser entendida também como uma dimensão do pensamento, da técnica e da atividade produtiva. As grandes rupturas epistemológicas que transformaram o pensamento humano e o desenvolvimento tecnológico produziram, por percursos distintos, abalos profundos e mudanças significativas na produção de conhecimento na Arte, na Ciência e na Filosofia. Tais transformações são ao mesmo tempo paralelas, por vezes sincrônicas, e independentes. Arte e ciência, portanto, são modos de manifestação do pensamento, são formas distintas de produção de conhecimento e não há uma hierarquia entre elas.

\section{O diálogo Ciência e Arte}

Do século XIX até os nossos dias, a Ciência e a Arte se consolidaram como dois "Campos" independentes, cada um com as suas especificidades, lógicas internas, divisões, formações discursivas, relações de poder e hierarquias próprias. Para Bourdieu (1989), um Cam- po pode ser definido como uma rede ou como um conjunto de relações objetivas entre posições definidas a partir das diferentes posições que os atores (sujeitos, agentes ou instituições) ocupam numa determinada situação (atual ou potencial) na estrutura da distribuição das diferentes espécies de poder (ou de capital). A posse de tal capital proporciona uma posição hierárquica (dominação, subordinação, dependência, homologia etc.) em relação aos outros atores que participam do mesmo jogo. Esse poder hierárquico que é estruturado e ao mesmo tempo estrutura as ações e define as relações no campo que, por sua vez, é dinâmico e mutável, refletindo a dinâmica das posições e das relações de poder próprias a cada campo.

A concepção de arte e ciência que temos hoje reproduz não apenas o nosso habitus de classe, como também a forma como esses saberes estão estruturados na sociedade. $\mathrm{Na}$ acepção de Bourdieu (1989), a memória do campo é assimilada e repetida quase que automaticamente por meio do habitus, que é um sistema de disposições duradouras adquiridas pelo indivíduo durante o processo de socialização. 0 habitus nos fornece os esquemas de percepção e apreciação, as estruturas cognitivas e avaliadoras, os modos de compreensão e reprodução do mundo social, de modo a organizar as condições objetivas de existência em princípios de ação, percepção e reflexão quase que inconscientes. Os comportamentos e valores aprendidos são considerados como óbvios, naturais, reproduzindo as regras sem reflexão. Para aproximarmos ciência e arte, torna-se então necessário conhecermos cada Campo e, a partir daí, buscarmos outra dimensão do pensamento que possa identificar os pontos divergentes, encontrar pontos convergentes, trazer à tona o que está por trás de cada discurso, método ou teoria, de modo a conhecer melhor cada um dos dois campos para saber como entendê-los e articulá-los.

0 processo de industrialização da ciência e de mercantilização da arte refletem, cada um a seu modo, os compromissos desses cam- 
pos com os centros de decisão do poder econômico, social e político, que cada vez mais vão influenciar, interferir, intermediar, direcionar e definir as "prioridades" do pensamento científico. Bourdieu (2004) afirma que o campo científico é um mundo social e, como tal, faz imposições, solicitações - que são, no entanto, relativamente independentes das pressões do mundo social global que o envolve. Contudo, essa independência é sempre relativa, o grau de autonomia ou heteronomia de um campo se dá de acordo com a sua capacidade de negociação com o mundo exterior e peso político ou econômico na hora da decisão.

0 campo científico é um campo de forças e, como tal, a dinâmica e a importância social de seus atores influenciam no que ele pode ou não fazer. É a posição que eles ocupam na estrutura social que determina ou orienta suas tomadas de posição. A estruturação interna do campo pode ser determinada pela distribuição do capital científico dentro do campo, mas ela também sofre influência dos fatores externos. Segundo Bourdieu (2004), os agentes (indivíduos ou instituições) caracterizados pelo volume de seu capital determinam a estrutura do campo em proporção ao seu peso, que depende do peso de todos os outros agentes, isto é, de todo o espaço. Dessa forma, a racionalidade científica e a produção artística estão impregnadas das questões existentes nas suas bases sociais, visto que elas sofrem os efeitos políticos e econômicos das suas formas de inserção na vida social.

Para conciliarmos, ou pelo menos, criar canais de diálogo entre a arte e a ciência, torna-se necessário recorrermos a outro modo de produção de conhecimento que permita analisar cada campo e perceber quais são as barreiras que impedem esse diálogo. Para nós, a filosofia é a forma de conhecimento que pode promover a reflexão mais profunda e a análise mais precisa desses dois campos, com eles e a partir deles. Enquanto ciência e arte reforçam suas características e linguagens próprias, a filosofia pergunta qual é a significação do que está sendo proposto por cada campo; que motivações estão presentes em cada estrutura de pensamento; qual formação discursiva está sendo produzida; qual é o sentido, o significado, a utilidade, o valor, a intenção e a finalidade do que está sendo pensado, dito e feito. Nossa hipótese é de que a Filosofia poderá, quiçá, construir as necessárias pontes entre estes Campos.

No decorrer da disciplina tentamos compreender as formas de atuação da Ciência e da Arte, analisando suas características, linguagens, métodos e processos. A Filosofia foi o eixo central da nossa reflexão e a referência principal se deu a partir da obra do pensador francês Gilles Deleuze (1992), que entende a Arte, a Filosofia e a Ciência como as "três asas do conhecimento". Como três formas independentes de criação, com formas distintas de compreensão e ação, cada uma operando a partir de suas características - sendo que uma não é mais importante que a outra, elas são complementares. Elas produzem, juntas, formas criativas de compreensão da realidade que potencializam umas às outras.

Filósofos, artistas e cientistas são, antes de tudo, pensadores. E essa é a questão central de Deleuze (2006): Como acontece o pensamento? Como se produz pensamento na filosofia, na ciência ou na arte? Afinal, não é só a filosofia que pensa, que produz ldeias. Para ele, as Ideias são invenções que podem se manifestar na pintura, na escultura, na produção de um conceito filosófico, na literatura, na criação de uma teoria científica, de um artefato tecnológico ou na concepção de um filme para o cinema. Entretanto, não se tratam de invenções de uma mesma natureza, pois cada uma delas possui uma órbita própria e uma forma própria de se manifestar e criar ldeias. Todas possuem em comum um mesmo desejo de produzir, inventar, criar. Para ele, as Ideias são multiplicidades, cada Ideia é uma multiplicidade, uma variedade de proposições, definida por $n$ dimensões.

Segundo Roberto Machado (1990), o objeto principal da filosofia de Deleuze é o exercício do pensamento, que, segundo ele, não é objeto exclusivo da filosofia. Para Machado, 
[...] o que interessa são as relações entre arte, ciência e filosofia. Não existe privilégio de uma dessas disciplinas sobre as outras. Cada uma delas é criadora. 0 verdadeiro objeto da ciência é criar funções, o verdadeiro objeto da arte é criar agregados sensíveis e o objeto da filosofia é criar conceitos. (p. 04)

Todavia, a filosofia não produz conceitos para ilustrar os outros campos do conhecimento, sua função não é explicar ou descrever esses campos. Não se trata de produzir conceitos sobre o cinema, sobre a Arte ou sobre a Ciência. A filosofia não é

[...] um metadiscurso ou uma metalinguagem que tem como objetivo formular ou explicitar critérios de legitimidade ou de justificação, e reivindicar para ela a produção de conhecimento ou, mais propriamente, a criação de pensamento. (Machado, 1990, p. 02)

Segundo Machado (1990), para Deleuze "não há reflexão sobre, e sim, pensamento a partir, ou melhor, com..." (p. 05). A questão que a filosofia coloca é: como encontrar ou estabelecer conexões, identificar ressonâncias de um campo no outro? Como as ldeias são criadas e se propagam na Arte ou na Ciência? Como refletir sobre elas?

A ciência não produz conceitos - essa é a tarefa da filosofia -, a ciência produz funções, proposições, hipóteses, modelos de explicação dos fenômenos. Uma noção científica é determinada não por conceitos, mas por funções ou proposições, e os elementos das funções, Deleuze (1992) os chama de functivos. Uma proposição científica pode utilizar um determinado número de conceitos, mas ela sempre se apropria deles com a intenção de reunir, ordenar, organizar e, para tal, ela fragmenta, parcela extratos potenciais, estabelece limites e intervalos. "A função, na ciência, determina um estado de coisas, uma coisa ou um corpo que atualizam o virtual sobre um plano de referência e num sistema de coordenadas" (p. 172). Procedendo assim, a ciência produz uma desaceleração, um modelo cristalizado de compreensão, que funciona a partir de variáveis predeterminadas e fixadas.

Para Deleuze (1992), a arte produz afectos e perceptos, ou seja, formas de divulgação, ampliação e diversificação da percepção, ela conecta o sujeito com o desejo, com o que lhe afeta, com "blocos de sensações" que ampliam sua capacidade de ser e existir. A filosofia, por sua vez, produz conceitos, que ele chama de conceptos, são reflexões, ideias ordenadas em um procedimento meticuloso de análise que nos ajudam a produzir formas de compreensão das proposições da ciência ou dos afectos e perceptos da arte. "A filosofia é a arte de formar, de inventar, de fabricar conceitos" (p. 10). No entanto, pensar é pensar por functivos, conceptos, afectos e perceptos. É preciso então que arte, filosofia e ciência aprendam a pensar a partir de outros critérios para enriquecer os critérios existentes. Para ele,

\section{[...] a filosofia precisa de uma não-filoso- fia que a compreenda, ela precisa de uma compreensão não-filosófica, como a arte precisa da não-arte e a ciência da não-ci- ência. (p. 279)}

Deleuze (1992) ressalta o papel da intuição, dos afetos e das intensidades na produção de conhecimento, na criação de ldeias e de novas possibilidades de percepção. Não se trata de desvalorizar os princípios da racionalidade científica ou de valorizar o pensamento artístico e sim de conhecê-los, identificar seus processos e ampliálos. Só assim, podemos criar ferramentas teóricas e estratégias pedagógicas que ampliem a capacidade criativa, produzindo novos conceitos e novas percepções do fazer artístico e científico, enriquecendo a discussão e a análise crítica de cada campo e produzindo formas mais intensas, relevantes e apaixonantes de estudar ciência e/ou arte. A proposta do curso, entretanto, não se limitou ao estudo do pensamento de Gilles Deleuze sobre o tema. Outros autores foram lidos e discutidos - autores que partem de princípios e formações teóricas distintas acerca da relação ciência e arte. 
A obra de Deleuze, portanto, foi uma referência importante, mas não a única, embora tenha de fato sido o ponto de partida e de apoio para problematizar e analisar outras correntes do pensamento, refletindo acerca da relação Ciência e Arte e buscando alternativas para a produção do conhecimento e também para a descoberta de novos caminhos para o ensino de ciências.

Nossa proposta de conciliar Arte e Ciência vai ao encontro da necessidade de buscar novos rumos na educação e na formação profissional, a partir da criação de instrumentos teóricos e estratégias pedagógicas que facilitem e potencializem o aprendizado de ciências. Imersos no campo da Ciência, como pesquisadores da Fiocruz que somos, a aproximação com o campo da Arte parece ser uma boa alternativa, pois ela amplia a criatividade e a percepção e enriquece o ensino das ciências. Uma nova forma de produção de conhecimento deve, necessariamente, buscar canais de diálogo entre os diferentes saberes. No século XXI, a Educação deve estimular o uso total da inteligência, o livre exercício da curiosidade e o diálogo entre saberes, a criatividade e a criação de diferentes formas de percepção e ação.

\section{O percurso da disciplina}

Nosso interesse, ao criar a disciplina, não era de utilizar a arte para ilustrar as teorias científicas nem de utilizar teorias científicas para respaldar ou "explicar objetivamente" os movimentos artísticos. Trata-se de perceber como o pensamento é produzido em cada campo e pensar junto, buscando um diálogo entre eles, tentando extrair deles uma nova imagem do pensamento. A opção pela filosofia se dá exatamente para potencializar a produção de pensamentos, Ideias e conceitos que nos ajudem a problematizar e pensar com esses dois campos do saber. Em vez de buscarmos um conjunto de regras ou tentarmos criar modelos que poderiam limitar a questão e empobrecê-la, optamos buscar um saber que não nos oferece respostas prontas e acabadas, mas nos ajuda a produzir perguntas, elaborar questões e propor novos problemas, ampliando o pensamento e problematizando as formas atuais de (re)produção do conhecimento.

Ao invés da contenção, da redução do conhecimento a representações que se pretendem únicas e inquestionáveis, verdades indiscutiveis ou modelos que engessam o pensamento, buscamos a expansão, a multiplicidade e o prazer na criação de novas ideias. Nesse sentido, a obra de Gilles Deleuze é a que ofereceu a abordagem que melhor se coadunou com a nossa proposta. Ao questionar rigidez dos princípios de uma racionalidade científica que busca o padrão, a uniformização e a normatização do pensamento e, por outro lado, ao valorizar a sensibilidade, o afeto, a diferença, a criatividade e o desejo, Deleuze vai conceber a produção de conhecimento como criação, invenção, constituição de processos intensivos, na qual a intensidade do desejo do sujeito, seja ele artista ou cientista, ocupa um lugar fundamental.

Deleuze combatia tudo que apequenava a vida e reduzia a criatividade, a intuição e a imaginação. Trabalhava contra os poderes que diminuem a alegria e separam os sujeitos das suas forças ativas, do desejo e da sua força vital, pois o desejo é quem libera as forças criativas, os fluxos de intensidades, a alegria e a imaginação, e a sua ausência, por outro lado, estimula a repetição de padrões estabelecidos, formas pouco criativas de viver e pensar. Sem desejo não há criação, só repetição sem questionamento. Devemos então criar agenciamentos, formas de pensamento que traduzem desejos coletivos, formas múltiplas de pensamento que produzem intensidades, afetos e acontecimentos que envolvem os indivíduos e potencializam suas formas de atuação, suas formas de devir, de estar no mundo, de se tornar o que se quer ser. Produzindo percepções que levam a novos posicionamentos e possibilitam a criação de novos territórios. As palavras acima destacadas são alguns conceitos presentes na obra de Deleuze que serviram como palavras-chave para analisar o "estado 
da arte" e promover novas discussões e reflexões no campo.

A busca por um diálogo entre a arte e a ciência reforça essa tentativa de criação de novos lugares, diferentes territórios, que possam levar à criação de outras formas de pensar, estudar e ensinar. Ao longo do curso, a partir das discussões dos textos e da análise de cada posição, tivemos a oportunidade de aprofundar a discussão, reformular ideias, criar propostas, debater, enfim, inventar uma nova forma de ensino no campo das ciências, tornando alunos e professores mais interessados e importantes. No entanto, sabemos que isso não é simples, que existem resistências, preconceitos e cristalizações que impedem a chegada de novas ideias. A simples menção, no meio científico mais tradicional, da tentativa de articulação de saberes tão díspares como a filosofia, a ciência e a arte já geram incertezas e resistências, pois a chegada de um novo saber pode desestabilizar o que está constituído e isso nem sempre é bem visto. 0 simples fato de não existir um campo para envio de projetos ou linhas de pesquisa que articulem saberes diferentes nas instituições de fomento já é um sintoma de que essa articulação não necessariamente é bem-vinda.

A realização dessa disciplina foi ao encontro da necessidade de um grande número de profissionais em aprofundar teoricamente as questões acerca da interface Ciência e Arte entre eles, vários profissionais do campo da Saúde ou das Ciências Humanas que já realizam ações a partir dessa interface. São profissionais de diversas áreas que possuem em comum o interesse em articular esses campos, pois já fazem isso nas suas práticas cotidianas, mas que buscam uma fundamentação teórica que sustente suas proposições. Sabemos que uma disciplina com esse perfil pode ser construída a partir de um número infinito de possibilidades, porém o que queremos expor aqui é a nossa experiência, a nossa tentativa, com todos os limites e equívocos que são próprios desse tipo de experimentação, para que os nossos erros, equívocos e omissões sirvam de referência ou base de discussão para outras disciplinas que tenham interesses e perspectivas comuns. Não se trata de construir um curso que deva ser reproduzido com os mesmos princípios, tratase apenas do relato de uma experiência que pode ajudar a fomentar a discussão no campo, incentivar o diálogo entre artistas e cientistas e servir de base de discussão (até para ser evitada) para novas iniciativas ${ }^{2}$.

\section{Os princípios norteadores da disciplina}

Ao pensar na articulação entre a arte e a ciência, temos então que perguntar quais são os agenciamentos que buscamos e criamos, quais seriam os nossos parceiros e quais seriam os nossos inimigos com quem nos aliamos e contra quem falamos. Sabemos que a potência nasce do coletivo e não dos indivíduos. A capacidade de criar um campo ou articular esses saberes não é tarefa isolada, é fruto da ressonância, do diálogo entre os atores que compõem a cena e da intensidade e competência desse diálogo. É preciso, portanto, avaliar as associações possíveis para constituição da disciplina, as composições que possam tornar a articulação viável, os estilos de fala, ou seja, os fundamentos teóricos que compõem a fala, o lugar de quem fala e a escolha do território a ser explorado. Cada um desses itens define os agenciamentos que criamos e participamos, a possibilidade dos deslocamentos e os vínculos que se estabelecem, pois sabemos que a constituição de um novo campo de saber não é apenas uma questão ontológica, de origem, é uma questão política. É preciso conhecer o território no qual se atua, a dinâmica do jogo, ter a noção do conjunto, do peso dos atores envolvidos, os movimentos possíveis e o espaço que os atores envolvidos no processo vão se situar. Criar uma disciplina que fuja aos padrões rígidos da academia, que articule formas

2. 0 conteúdo programático das aulas e as referências bibliográficas do curso encontram-se anexos. 
distintas de pensar, ao mesmo tempo em que detém também o rigor científico necessário, com um método coerente e uma fundamentação teórica consistente, dentro de uma instituição reconhecida internacionalmente como referência na área de Saúde, não é tarefa simples, posto a própria necessidade da existência da disciplina não ser nem mesmo uma unanimidade entre os pares.

Com Foucault (2005), aprendemos que a realidade material do discurso, seja ele científico ou artístico, supõe uma relação de poder, um lugar de lutas, vitórias, conflitos e ferimentos. Os discursos não existem sem pressão, sem violência, e criar disciplinas novas, que articulam saberes distintos e que coloca em cheque o saber disciplinar estabelecido, não ocorre de forma neutra - pois o discurso é uma ferramenta de poder e, ao se propor uma nova forma de pensar o poder estabelecido, os mecanismos de inclusão e exclusão aparecem.

0 modelo científico hegemônico se impõe, direciona o saber, as funções, os modos de pensar dos sujeitos cognoscentes e dita seus métodos, processos e instrumentos que validam sua forma específica de produção de conhecimento. Tal conjunto de saberes, em geral, estabelece-se a partir de um corpo institucional que reforça a manutenção das práticas, das ações e dos processos cognitivos. Produz uma espécie de pressão, de coerção no sentido de uma forma de racionalização que classifica, ordena, hierarquiza e distribui seus mecanismos de poder. A criação de uma nova disciplina ou um novo campo de saber, em geral, desestabiliza o jogo e obriga os atores a se reposicionarem, o que nem sempre é confortável ou agradável para quem já estava em uma posição de poder estabelecida.

0 conhecimento disciplinar especializado pressupõe um conjunto de códigos, regras, identidades e procedimentos que estruturam um corpus de proposições consideradas verdadeiras, que podem ser repetidas independentes do seu autor. Para que haja a disciplina, é preciso que haja a possibilidade de se formular proposições novas, a partir de uma base co- mum, preestabelecida. Os campos de saber se apropriam da linguagem corrente e constituem sistemas de saber, dotados de valores simbólicos, que validam os instrumentos conceituais para quem compartilha dos mesmos códigos. Uma proposição precisa ser compartilhada pelos componentes de um mesmo campo para ser aceita e respeitada, ela precisa estar de acordo com o modelo vigente, o paradigma aceito por todos. Nesse sentido, não basta dizer a verdade, é preciso dizer a verdade a partir do discurso corrente, a partir do que é considerado verdadeiro, pois o verdadeiro existe a partir de regras de uma "política discursiva que devemos reativar em cada um dos nossos discursos". Segundo Foucault (2005), "ninguém entrará na ordem do discurso se não satisfizer a certas exigências ou se não for, de início, qualificado para fazê-lo" (p. 36-37).

No entanto, as questões que se colocaram para nós foram: Como criar uma disciplina que concilia campos aparentemente inconciliáveis? Como falar de Arte e Ciência sem conhecer as regras do jogo em cada campo? Como conciliar os teóricos desses dois campos? Como criar um diálogo entre esses campos e transformar isso em uma ferramenta didática que possa ser divulgada e analisada? Quem poderia fazer essa ponte? Que autor ou que autores poderíamos utilizar para nos fundamentar?

Era fundamental encontrar um autor que conciliasse esses diferentes campos e nossa escolha se deu a partir da leitura da obra de Gilles Deleuze (2004), que é um dos autores que melhor articula o diálogo entre as "três asas do conhecimento" (a Arte, a Filosofia e a Ciência), colocando-as num mesmo patamar de importância. Dentre os conceitos que ele criou, uma das ideias que utilizamos no nosso trabalho é a de "agenciamento coletivo de enunciação". A partir desse conceito, ele expõe uma forma de construção de pensamento que não obedece à lógica linear da construção científica. Essa ideia se aproxima do conceito de rizoma que, por sua vez, contrapõe-se ao conceito de "árvore do conhecimento" que comentaremos a seguir. 
A imagem do pensamento tradicional supõe um encadeamento que pode ser representado pela imagem da árvore do conhecimento, com o seu tronco único a partir das ciências naturais e suas diversas ramificações, que representariam as especializações científicas - como se os galhos dessa árvore crescessem de forma independente e sem possibilidade de comunicação entre si. Pelo contrário, quanto maior o nível de especialização, maior a distância entre as partes que a compõe. 0 Rizoma, ao contrário, utiliza a metáfora da raiz, de uma ramificação que não tem uma origem única e que pode se espalhar por um determinado território. 0 rizoma não obedece à lógica linear da racionalidade científica, e o pensamento, da mesma forma, também não obedece a essa lógica sistêmica.

A Arte, a Filosofia e a Ciência são três formas distintas de produção de conhecimento, mas não são as únicas. A religião e o senso comum, por exemplo, são também duas poderosas formas de produção social de sentidos e de entendimento da realidade. Cada uma delas opera a partir de uma lógica interna própria e são complementares, coincidentes, não havendo a sobreposição de uma sobre a outra ou de anulação de uma diante da outra. 0 conhecimento, portanto, acontece a partir de um processo de heterogênese. Ele é produzido a partir de diversas instâncias e surge a partir de diferentes origens. A produção do pensamento não ocorre de forma mecânica e sistêmica nem é organizado e linear como supõe a racionalidade científica, pelo contrário, ele surge a partir de diferentes circunstâncias nas quais o desejo, os afetos, as circunstâncias e os acontecimentos produzem diferentes agenciamentos, associações e movimentos.

Os agenciamentos coletivos de enunciação traduzem essa multiplicidade de desejos, devires e afetos que envolvem os indivíduos e suas intensidades de existir (Deleuze, 2004). Eles se compõem de quatro elementos principais: o estado das coisas, os estilos de enunciação, os territórios e os movimentos. 0 "estado das coisas" fala da dinâmica do jogo, do contexto, dos diferentes interesses que compõem o campo acadêmico e que não permite (ou dificulta) a constituição de uma disciplina ou de um saber que articule diferentes instâncias do pensamento. Refere-se, portanto, às tensões conjunturais, à paisagem, à forma como o saber se constitui por especializações e aos mecanismos criados para a manutenção da ordem. Os "estilos de enunciação" falam dos dispositivos retóricos, argumentativos ou teóricos que se contrapõem à tentativa de se criar uma disciplina nova, às tentativas de desqualificação do saber constituído contra outras formas de saber em processo de constituição. Fala também dos modos de organização dos signos e das bases de organização dos discursos, porque no campo científico a opção por utilizar um conjunto de terminologias, conceito ou teorias já exclui a possibilidade de trazer novas ideias à cena. Os "movimentos" se referem às percepções dos estados das coisas e das possibilidades de criação de novos posicionamentos dos sujeitos, observando a dinâmica do jogo, seus ritmos, fluxos, interesses e temporalidades. Criando linhas de fuga, alternativas à ordem estabelecida e a possibilidade de transitar por outros territórios. E finalmente, os "territórios" se referem aos espaços que precisam ser destruídos (desterritorialização), refeitos (reterritorialização) e ocupados (territorialização).

\section{As principais referências da disciplina}

A partir de Gilles Deleuze, que é a nossa referência principal, tentamos identificar algumas de suas influências para entender a partir de que posição ele fala e contra quem fala. Ao analisar suas influências, alguns nomes se destacam imediatamente, entre eles, Espinosa, Bergson e Nietzsche. Esses três autores não apenas são fundamentais na obra de Deleuze, como também dão o tom da disciplina. A partir deles, podemos pensar nossos próprios agenciamentos, movimentos e territórios. Outros autores e assuntos fizeram parte do reper- 
tório de Deleuze. Poderíamos citar os diferentes livros dele que trataram de filósofos como Hume (Deleuze, 2001), Kant (Deleuze, 1963) e Leibniz (Deleuze, 1991), de escritores como Kafka (Deleuze, 1977) e Proust (Deleuze, 2003), de um pintor como Francis Bacon (Deleuze, 2007), e de temas como o cinema (Deleuze, 1990) ou a psicanálise (Deleuze, 1976). No entanto, os três autores citados inicialmente compõem a estrutura principal, a espinha dorsal do pensamento deleuziano e, devido ao espaço limitado deste artigo, limitamo-nos a mencionar esses três autores que consideramos fundamentais para Deleuze e ganharam destaque na formulação da disciplina.

Da obra de Espinosa (1632-1677), ele retira a ideia de univocidade do ser, a noção de uma imanência que se contrapõe à transcendência platônica, que separa pensamento e matéria. Espinosa se baseia na ideia de um Deus que possui atributos infinitos, mas que é um único ser, imanente, que se manifesta por meio de uma única substância para todas as coisas, materiais ou imateriais, pensamento ou matéria. E tudo o que existe é expressão desse Deus, dessa Natureza que se manifesta em todas as coisas, conciliando pensamento, matéria e ação (Deleuze, 2002). Nesse sentido, a existência deixa de algo decidido externamente ou predeterminado por uma ordem divina. Ela passa a ser o resultado das escolhas do indivíduo, dos afetos e das paixões que ele se deixa envolver, sejam esses afetos positivos ou negativos.

Para Espinosa, o corpo é um sistema complexo de movimentos internos e externos. Ele é relacional, formando um sistema de ações centrípeto e centrífugo, constituído por relações internas entre seus órgãos e com relações externas com outros corpos. É constituído por afecções, isto é, pela capacidade de afetar e de ser afetado por outros corpos e ser afetado por eles sem se deixar destruir, regenerando-se com eles e os regenerando (Chauí, 2000). Um corpo compõe com o meu quando aumenta minha potência, amplia minha força vital e potencializa minha capacidade de ação. Por outro lado, um corpo pode também diminuir minha potência, esvaziar ou diminuir minha força vital e reduzir minha capacidade de ação. E esses encontros que determinam a existência, traduzem uma forma plena de existir ou, ao contrário, apequenam a existência, reduzindoa a simples sobrevivência. Para Espinosa, os bons ou maus encontros não são fruto de uma ordem divina nem obedecem a uma regulação moral exterior ao sujeito, pois somos nós que escolhemos nossas relações, nossos afetos e definimos o curso da nossa existência. Nós nos relacionamos com afetos positivos e negativos e somos nós mesmos que escolhemos a manutenção ou não desses afetos.

Deleuze percebe em Espinosa um pensamento que afirma o desejo, que coloca corpo e alma como indissociáveis, atuando de forma ativa e passiva, traduzindo uma imanência que coloca alma e corpo juntos e por inteiro, sem relações hierárquicas entre eles. 0 corpo não é uma máquina como afirmava Descartes, não é apenas um feixe de músculos, nervos e funções numa estrutura mecânica que separa as sensações corpóreas do pensamento. 0 corpo, para Espinosa, também não é túmulo ou prisão da alma como afirma o platonismo. Ele está em relação com os afetos, com os desejos e com as paixões, sejam elas alegres ou tristes.

0 corpo humano é uma unidade estruturada, não é um agregado de partes, mas unidade de conjunto e equilíbrio de ações internas interligadas de órgãos. Os apetites do corpo refletem os afetos da alma, pois os corpos são relacionais, eles estão necessariamente em relação uns com os outros e, nesses encontros, o meu corpo tanto pode ampliar ou reduzir sua potência, sua capacidade de ação. Nem o corpo comanda a alma nem a alma comanda o corpo como afirmava a tradição do pensamento ocidental. Para ele, corpo e mente se fundem e manifestam a correspondência entre os acontecimentos psíquicos e corporais, manifestando a causalidade única da Substância (Deus/Natureza). Essa percepção aponta para a responsabilidade do sujeito e a intensidade e capacidade reflexiva que ele possui acerca de sua própria 
existência. A intensidade do desejo é quem determina a poética da existência.

Nietzsche (1844-1900), da mesma forma, afirma essa intensidade da vida e a busca por uma existência plena de vontade de potência (que não pode ser confundida com uma vontade mesquinha de apropriação de um poder que manipula e apequena a vida). A existência, para Nietzsche, é cheia de paixões, desejos e vontades que se referem à vida e à expansão da nossa força vital, portanto, não se referem espontaneamente ao bem e ao mal, pois estes são uma invenção da moral racionalista que foi erguida com uma finalidade repressora, e não para garantir o exercício da liberdade (Deleuze, 2001).

Para Nietzsche, não existe uma alma superior que subordina a verdade. Esta é subordinada às paixões do corpo, é integrada ao corpo numa relação de pura imanência, sem transcendência alguma. Ou seja, o corpo assim como a razão, o intelecto, a ciência e seus conceitos são instrumentos colocados à disposição de seu dono de modo a expandir sua vitalidade e sua potência. 0 corpo, da mesma forma, não é apenas um conjunto mecânico de peças estranhas umas às outras, ele é um jogo flexível de peças que se confrontam e estabelecem uma relação dinâmica entre elas (Levine; Touboul, 2002). Ele também se insere nessa pluralidade de forças, de pulsões, de paixões, de interesses e vontade de potência que visam construir um mundo de acordo com uma necessidade particular. Ele não é apenas um conjunto, é uma hierarquia de forças "subordinadas" ou "dominantes" - colocadas em relação de comando ou obediência. Tal conjunto reproduz relações de força que lutam entre si, buscando obter o comando, mas que falam a mesma linguagem, isto é, num mesmo corpo, habitam uma pluralidade de espíritos, de vontades ou de consciências, que criam uma hierarquia que, ao mesmo tempo, traduz um conflito interno e uma compreensão mútua entre as vontades. Permitem uma forma de coesão a partir da diferença, são vontades divergentes que se equilibram e se ajustam mutuamente.
Nietzsche propõe uma reflexão sobre a ciência, ou seja, uma investigação sobre as questões relativas ao conhecimento, às condições de produção do pensamento, da razão, da consciência, do conceito e, principalmente, da verdade e dos valores que constroem o monopólio da verdade (Deleuze, 2007). Para ele, essa busca metafísica dos valores revela uma necessidade humana de segurança e garantia, pois o instinto humano é passivo, fraco e reativo. E o homem não consegue confrontar-se com a crueldade da realidade nem com a vida como processo de mudança constante. E os valores morais são históricos, são resultado da produção humana, são interpretações produzidas pelo homem para melhor se adequar ao mundo. Sendo assim, não existem valores morais universais, transcendentes. Os valores devem ser avaliados a partir de sua força, de sua possibilidade de ampliar ou reduzir a potencialidade da vida. Todos os valores são sintomas que devem ser interpretados a partir dessa pluralidade de forças, e a moral, ao lado da ciência e da religião, é o resultado da necessidade de carregarmos máscaras, da necessidade de mentir, são mentiras sem as quais não podemos viver, mas cujo caráter de mentira é esquecido.

Com Bergson (1859-1941), a questão corpo versus mente ganha outros ingredientes. Para ele, corpo e espírito se distinguem por diferenças de ritmo, natureza e grau, e o ambiente onde estas distinções acontecem é o Tempo. Em sua obra, Bergson (1990) afirma que "nosso corpo é um instrumento de ação e somente de ação" (p. 16). A função do corpo físico é produzir a percepção imediata das coisas, servindo apenas para selecionar imagens com vista à ação, e a consciência, que é memória, independe do corpo. Segundo ele, "meu corpo, objeto destinado a mover objetos, é portanto um centro de ação; ele não poderia fazer nascer uma representação" (p. 14).

Bergson relaciona o corpo à percepção e a consciência à memória, esta sim ligada ao espírito. Segundo ele, existem dois tipos de memória: a pura, que é a verdadeira, atividade 
puramente espiritual, e a hábito, que não passa de instrumento motor da primeira. Enquanto a memória pura é uma extensão da consciência e possui uma duração, a memória hábito é transitória, "move-se num presente que está sempre recomeçando". A memória pura, essencialmente contemplativa e desinteressada, registra o singular em si e por si. Já a "memória hábito, essencialmente motora, serve à ação e, com esse objetivo, converte o particular em geral" (Huisman, 2001, p. 139).

Ou seja, a necessidade de agir no mundo material faz com que a percepção trace as ações virtuais ou possíveis do corpo, e o que ele chama de matéria é apenas esse conjunto de imagens captadas pelo cérebro. Segundo Bergson (1990), “o cérebro nos parece um instrumento de análise com relação ao movimento executado [...]. Equivale a dizer que o sistema nervoso nada tem de um aparelho que serviria para fabricar ou mesmo preparar representações” (p. 27). Ou seja, enquanto a percepção é apenas um dado imediato da consciência, é a memória que constitui a subjetividade; enquanto a percepção é efêmera, a memória prolonga uma pluralidade de momentos. "Mesmo a 'subjetividade' das qualidades sensíveis [...], consiste sobretudo em uma espécie de contração do real, operada por nossa memória” (p. 31).

No entanto, a memória não consiste numa regressão ao passado, ao contrário, ela é o passado que se faz presente, que se materializa numa percepção atual e se torna um estado presente e atuante no nosso corpo. Essa memória, agindo no presente, resgata a lembrança na percepção, fazendo com que o presente se torne intenso, carregado de planos de consciência diferentes. 0 presente

[...] é o que age em nós e o que nos faz agir, ele é sensorial e motor, nosso presente é antes de tudo o estado do nosso corpo. Nosso passado é o que não age mais, mas poderia agir, o que agirá ao inserir-se numa sensação presente da qual tomará emprestada a vitalidade. [...] Compreende-se por que a lembrança não podia resultar de um esta- do cerebral. 0 estado cerebral prolonga a lembrança; faz com que ela atue sobre o presente pela materialidade que lhe confere; mas a lembrança pura é uma manifestação espiritual. Com a memória estamos definitivamente no domínio do espírito. (Bergson, 1990, p. 281)

\section{Conclusão}

Essas três concepções, apresentadas por Espinosa, Nietzsche e Bergson, fundamentam a percepção de Deleuze acerca das propriedades do corpo, do sentido da existência e da função do desejo. Traduzem também a opção por uma crítica à racionalidade científica ocidental que hipervaloriza a razão e desvaloriza a imaginação, a criatividade e a intuição que, para Deleuze, são formas privilegiadas do pensamento e forças positivas que potencializam a existência. É importante ressaltar que essas concepções colocam em evidência um olhar sobre o corpo que vai além do paradigma atual da biomedicina, que ainda vê o corpo de forma mecanicista, reducionista e dualista, e a possibilidade de refletir acerca dessas diferentes concepções é fundamental para nós que trabalhamos com o ensino de ciências no campo da saúde.

Deleuze tinha horror a tudo que empobrecia a existência e tornava medíocre o pensamento. Para ele, a produção do conhecimento deve ocorrer em condições de liberdade, com a possibilidade de utilização da imaginação e da criatividade, sem ficar preso às formas rígidas e tradicionais do pensar. Nesse sentido, a intuição ganha um lugar de destaque na constituição do pensamento, pois ela é uma compreensão global e completa de uma verdade, um objeto ou um conjunto de relações. Nela, de uma só vez, a razão capta todas as relações que constituem a realidade e a verdade da coisa intuída, pois ela é um ato intelectual de discernimento que engloba inúmeros procedimentos racionais armazenados na memória e, com a ajuda da imaginação e da criatividade, cria novas conexões e um novo conjunto de relações no qual só havia 
pensamentos dispersos e desconectados. A intuição dá ordem ao aparente caos.

A intuição é fundamental tanto na Arte quanto na Ciência, assim como a imaginação e a criatividade. No entanto, para conectá-las, é preciso acionar o desejo, a força vital de que falavam Espinosa, Bergson e Nietzsche. A intuição opera uma síntese que reúne fatos ou ações inexplicáveis no passado porque não eram percebidos de uma só vez. Ela cria uma síntese que permite articular e organizar um todo, estabelecer uma nova ordem de sentidos e criar articulações inusitadas. Além disso, permite ao sujeito, de uma só vez, perceber o objeto conhecido, relacionando suas formas, seus conteúdos, suas causas, relações, propriedades, efeitos, suas relações com outros objetos, assim como permite ao sujeito do conhecimento conhecer a si mesmo.

Tanto na Arte como na Ciência, a intuição é imprescindível, pois ela articula tanto as informações oriundas da sensibilidade, da imaginação, da experiência, do desejo ou das diferentes percepções da realidade, como também produz um conhecimento intelectual que se baseia nos princípios da razão (os princípios de identidade, contradição, do terceiro-excluído e da razão suficiente). A intuição não exclui a utilização da razão, ao contrário, ambas são formas de inteligência complementares e estão presentes nos diferentes processos cognitivos sejam eles artísticos e/ou científicos.

A imaginação, a intuição e a razão, juntas, produzem relações complexas que levam à emoção criadora, que produzem uma alegria que faz o corpo vibrar. Essa alegria é diferente do prazer momentâneo, ilusório, pois serve para a conservação e invenção da vida, pois onde há alegria, há criação. Quanto mais rica a criação, mais profunda é a alegria, seja na dimensão artística, científica, moral, existencial ou intelectual. Para Bergson, o élan da vida está na criação, não está na serialização e na repetição do conhecimento sem crítica. Está no movimento e não nas formas cristalizadas do saber e na paralisação em fórmulas de ensino desgastadas e ineficientes.

Nesse sentido, os três teóricos se aproximam, pois falam (a partir de conceitos diferentes) de uma mesma coisa, de uma mesma força inventiva que recria a vida. Isso pode ser identificado no conceito de "conatus" na obra de Espinosa, das paixões alegres proporcionadas pelo discernimento que o conhecimento traz. Como também no conceito de "duração" ou na ideia de evolução criadora da vida na obra de Bergson. Ou ainda no conceito de "eterno retorno" ao que nos dá prazer, nos alimenta e amplia nossa vontade de potência (em Nietzsche). Estamos sempre falando de uma forma positiva, criativa, inventiva de produzir conhecimento, seja no campo artístico ou científico.

Nossa proposta de conciliar a arte com o ensino de ciências, portanto, enquadra-se nessa perspectiva de criar estratégias pedagógicas que mobilizem pelo prazer, pela emoção e que valorizem a imaginação, a intuição e a criatividade. Que criem mecanismos de conexão dos alunos com o seu próprio desejo, fazendo-os perceber que tanto o trabalho artístico quanto o científico são formas de expressar a criatividade, de inventar novas possibilidades, de ampliar a percepção da realidade e de conceber novas leituras do mundo. Intuição e razão, criatividade e precisão, prazer e reflexão, corpo e mente, arte e ciência, não são pares opostos, são antes dimensões complementares da existência. 


\begin{tabular}{|c|c|c|c|}
\hline Aula & Tema & Conteúdo & Referências bibliográficas \\
\hline 01 & $\begin{array}{l}\text { Apresentaçăo geral do } \\
\text { curso e referencias } \\
\text { bibliográficas. } \\
\text { Por que Deleuze? }\end{array}$ & $\begin{array}{l}\text { Arte, Filosofia e Ciência como três formas } \\
\text { distintas de compreensăo da realidade e } \\
\text { produçăo de conhecimento. } \\
\text { Os conceitos de afectos, perceptos e } \\
\text { conceptos em Deleuze. }\end{array}$ & $\begin{array}{l}\text { "Filosofia, Ciência Lógica e Arte". DELEUZE, G. } \\
\text { O que é a Filosofia. Rio de Janeiro: Editora } \\
34,1992 \text {. }\end{array}$ \\
\hline 02 & $\begin{array}{l}\text { Do Mito à Razăo. } \\
\text { Cosmologia e } \\
\text { cosmogonia. }\end{array}$ & $\begin{array}{l}\text { Os pré-socráticos e a construção da } \\
\text { racionalidade. } \\
\text { A depreciação platớnica da Arte e a } \\
\text { legitimaçăo em Aristóteles. }\end{array}$ & $\begin{array}{l}\text { LACOSTE, J. A Filosofia da Arte. Rio de } \\
\text { Janeiro: Zahar, } 1986 . \\
\text { HAAR, M. A obra de arte: ensaio sobre a } \\
\text { ontologia das obras. Rio de Janeiro: Difel, } \\
2000 \text {. }\end{array}$ \\
\hline 03 & $\begin{array}{l}\text { A Filosofia, a Arte e as } \\
\text { Ciências Modernas }\end{array}$ & $\begin{array}{l}\text { O pensamento modemo, o humanismo e } \\
\text { as revoluçes cientificas. } \\
\text { Racionalismo e empirismo. }\end{array}$ & $\begin{array}{l}\text { ARGAN, G. C. Clássico e anticlássico: o } \\
\text { Renascimento de Brunelleschi a Bruegel. Săo } \\
\text { Paulo: Companhia das Letras, } 1999 .\end{array}$ \\
\hline 04 & $\begin{array}{l}\text { As paixōes da alma, as } \\
\text { dobras do espaco e } \\
\text { seus desdobramentos. }\end{array}$ & $\begin{array}{l}\text { O conceito de "dobra" e seus } \\
\text { desdobramentos nas artes e nas ciências. } \\
\text { As dobras da matéria, da matemática ao } \\
\text { barroco em Leibniz. As mónadas. }\end{array}$ & $\begin{array}{l}\text { DELEUZE, G. A dobra: Leibniz e o barroco. } \\
\text { Campinas: Papirus, } 1991 .\end{array}$ \\
\hline 05 & $\begin{array}{l}\text { O corpo como máquina } \\
\text { e como lugar dos afetos. }\end{array}$ & $\begin{array}{l}\text { A dualidade corpo-mente em Descartes e } \\
\text { Espinosa. } \\
\text { Dualismo x monismo. }\end{array}$ & $\begin{array}{l}\text { DESCARTES, R. As paixōes da alma. São } \\
\text { Paulo: Martins Fontes, } 1998 \text {. } \\
\text { ESPINOSA, B. Ética: demonstrada a maneira } \\
\text { dos geómetras. SAå Paulo: Martin Claret. } 2002 .\end{array}$ \\
\hline 06 & $\begin{array}{l}\text { A critica à Razão. } \\
\text { Nietzsche e a critica à } \\
\text { racionalidade cientifica. }\end{array}$ & $\begin{array}{l}\text { O Belo e o Sublime no romantismo } \\
\text { alemão. } \\
\text { Contra a razão despótica - Sturm und } \\
\text { Drung (tempestade e paixăo) - Karl } \\
\text { Friedrich/Wagner. }\end{array}$ & $\begin{array}{l}\text { MACHADO, R. Nietzsche e a Verdade. Rio de } \\
\text { janeiro: Roco,, } 1985 \text {. } \\
\text { DELEUZE, G. Nietzsche e a Filosofia. Porto: } \\
\text { Rés Editora, } 2001 .\end{array}$ \\
\hline 07 & A percepção do espaço. & $\begin{array}{l}\text { As geometrias nāo euclidianas, a teoria } \\
\text { da relatividade e as vanguardas artisticas } \\
\text { do inicio do século XX. A construçăo de } \\
\text { uma nova percepçấo do espaço em } \\
\text { Mondrian e Malevtich. }\end{array}$ & $\begin{array}{l}\text { ARGAN, G. C. Arte Moderna. São Paulo: } \\
\text { Companhia das Letras, } 1997 . \\
\text { BACHELARD, G. A poética do espaço. Såo } \\
\text { Paulo: Martins Fontes, } 1993 .\end{array}$ \\
\hline 08 & $\begin{array}{l}\text { Positivismo e } \\
\text { fenomenologia. }\end{array}$ & $\begin{array}{l}\text { A fenomenologia como um método que } \\
\text { pretende explicitar as estruturas da } \\
\text { experiência humana em sua relaçăo com } \\
\text { o real. }\end{array}$ & $\begin{array}{l}\text { MERLEAU-PONTY, M. O olho e o espírito e A } \\
\text { dúvida de Cézanne. Săo Paulo: Abril Cultural, } \\
\text { 1979. (Coleção Os Pensadores). }\end{array}$ \\
\hline 09 & Tempo e memória. & $\begin{array}{l}\text { A evoluçăo criadora, o élan vital e as } \\
\text { diferentes memórias em Bergson. } \\
\text { As ressonâncias de Bergson em Deleuze }\end{array}$ & $\begin{array}{l}\text { BERGSON, H. Matéria e memória: ensaio } \\
\text { sobre a relaçăo do corpo com o espirito. São } \\
\text { Paulo: Martins Fontes, } 1990 . \\
\text { DELEUZE, G. Bergsonismo. Săo Paulo: } \\
\text { Editora } 34,1999 \text {. }\end{array}$ \\
\hline 10 & Discurso e Poder & $\begin{array}{l}\text { As palavras e as coisas - o método } \\
\text { "arqueológico" e a construçăo do saber } \\
\text { cientifico. } \\
\text { A questāo do discurso na arte e na } \\
\text { ciência. A definiçăo dos enunciados e as } \\
\text { funç̧es da enunciaçăo. }\end{array}$ & $\begin{array}{l}\text { FOUCAULT, M. A ordem do discurso. São } \\
\text { Paulo: Ediç̋es Loyola, } 1996 . \\
\text { FOUCAULT, M. As palavras e as coisas: uma } \\
\text { arqueologia das Ciéncias Humanas. São } \\
\text { Paulo: Martins Fontes, } 1981 .\end{array}$ \\
\hline 11 & $\begin{array}{l}\text { Os usos sociais da arte } \\
\text { e da ciência. }\end{array}$ & $\begin{array}{l}\text { As relaçōes da arte e da ciência com o } \\
\text { mercado e os interesses de cada } \\
\text { "campo". A luta por hegemonia, os } \\
\text { conflitos e as disputas por mercado e } \\
\text { recursos. }\end{array}$ & $\begin{array}{l}\text { BOURDIEU, P.; HAACKE, H. Livre-troca: } \\
\text { diálogos entre Ciência e Arte. Rio de Janeiro: } \\
\text { Bertrand Brasil, } 1995 \text {. }\end{array}$ \\
\hline 12 & $\begin{array}{l}\text { A produçăo de novos } \\
\text { conceitos em Ciência e } \\
\text { Arte. }\end{array}$ & $\begin{array}{l}\text { O que é um conceito. } \\
\text { Os conceitos de "acontecimento", "devir", } \\
\text { "agenciamento" e "imanéncia" em } \\
\text { Deleuze. }\end{array}$ & $\begin{array}{l}\text { DELEUZE, G. O que é a Filosofia? São Paulo: } \\
\text { Editora 34, } 1992 . \\
\text { DELEUZE, G. Conversaçŏes. } \\
\text { Săo Paulo: Editora 34. } 1992 .\end{array}$ \\
\hline 13 & A sétima arte. & $\begin{array}{l}\text { Arte, ciência e filosofia no cinema. A } \\
\text { construção do tempo, da đuraçăo, đo } \\
\text { movimento e da imagem. }\end{array}$ & $\begin{array}{l}\text { DELEUZE, G. Imagem tempo. Såo Paulo: } \\
\text { Brasiliense, } 1990 \text {. } \\
\text { DELEUZE, G. Imagem movimento. Lisboa: } \\
\text { Assirio e Alvin, 2004. }\end{array}$ \\
\hline 14 & $\begin{array}{l}\text { O corpo em evidência. } \\
\text { Arte e Psicanálise. }\end{array}$ & $\begin{array}{l}\text { O conceito de "Corpo sem órgăos" em } \\
\text { Deleuze. }\end{array}$ & $\begin{array}{l}\text { Deleuze, G.; GUATTARI, F, Mil platôs: } \\
\text { capitalismo e esquizofrenia. Săo Paulo: Editora } \\
\text { 34, } 1996 .\end{array}$ \\
\hline 15 & $\begin{array}{l}\text { Pintura, Literatura elou } \\
\text { Filosofia. }\end{array}$ & $\begin{array}{l}\text { A criaçáo dos "blocos de sensaçбes" nas } \\
\text { obras de Kafka e Proust. } \\
\text { Como tomar visivel o invisivel? }\end{array}$ & $\begin{array}{l}\text { DELEUZE, G. Proust e os signos. Rio de } \\
\text { Janeiro: Forense universitária, } 2003 \text {. } \\
\text { DELEUZE, G. Kafka: por uma literatura menor. } \\
\text { Rio de Janeiro: Imago, } 1977 \text {. }\end{array}$ \\
\hline
\end{tabular}




\section{Referências bibliográficas}

ARGAN, G. C. Clássico e anti-clássico: o renascimento de Brunelleschi à Bruegel. São Paulo: Companhia das Letras, 1999.

Arte moderna. São Paulo: Companhia das Letras, 1992.

BACHELARD, G. A poética do espaço. São Paulo: Martins Fontes, 1993.

BERGSON, H. Matéria e memória: ensaio sobre a relação do corpo com o espírito. São Paulo: Martins Fontes, 1990.

BOURDIEU, P. 0 poder simbólico. Rio de Janeiro: Bertrand Brasil, 1989.

Os usos sociais da ciência: por uma sociologia clínica do campo científico. São Paulo: Ed. UNESP, 2004.

BOURDIEU, P.; HAACKE, H. Livre-troca: diálogos entre Ciência e Arte. Rio de Janeiro: Bertrand Brasil, 1995.

CARCHIA, G.; D’ANGELO, P. Dicionário de estética. Lisboa: Edições 70, 1999.

CHAUÍ, Marilena. "Paixão, ação e liberdade em Espinosa". Folha de São Paulo, São Paulo.Caderno Mais. 20 de agosto de 2000.

DELEUZE, G. Diferença e repetição. Rio de Janeiro: Graal, 2006.

A dobra. Leibniz e o barroco. Campinas: Papirus, 1991.

0 que é a filosofia. Rio de Janeiro: Editora 34, 1992.

Espinosa - Filosofia prática. São Paulo: Escuta, 2002.

Conversações. São Paulo: Editora 34, 1992.

Bergsonismo. São Paulo: Editora 34, 1999.

Empirismo e subjetividade. São Paulo: Editora 34, 2001.

A filosofia crítica de Kant. Lisboa: Edições 70, 1963.

Imagem tempo. São Paulo: Brasiliense, 1990.

Imagem movimento. Lisboa: Assírio e Alvin, 2004.

Proust e os signos. Rio de Janeiro: Forense universitária, 2003.

Kafka: por uma literatura menor. Rio de Janeiro: Imago, 1977.

Francis Bacon: lógica da sensação. Rio de Janeiro: Zahar, 2007.

0 anti-Édipo: capitalismo e esquizofrenia. Rio de Janeiro: Imago, 1976

DELEUZE, G.; GUATTARI, F. Mil platôs: capitalismo e esquizofrenia. Rio de Janeiro: Editora 34. 1996. (Volumes 1, 2, 3, 4 e 5).

DESCARTES, R. As paixões da alma. São Paulo: Martins Fontes, 1998.

ESPINOSA, B. de. Ética - demonstrada à maneira dos geômetras. São Paulo: Martin Claret, 2002.

FOUCAULT, M. A ordem do discurso. São Paulo: Loyola, 2005.

As palavras e as coisas: uma arqueologia das Ciências Humanas. São Paulo: Martins Fontes, 1981.

FOUCAULT, M. A ordem do discurso. São Paulo: Loyola, 1996. 
HAAR, M. A obra de arte: ensaio sobre a ontologia das obras. Rio de Janeiro: Difel, 2000.

HUISMAN, D. Dicionário dos filósofos. São Paulo: Martins Fontes, 2001.

JIMENEZ, M. 0 que é estética? São Leopoldo: Unisinos, 1999.

LACOSTE, J. A filosofia da arte. Rio de Janeiro: Zahar, 1986.

LÉVINE, E.; TOUBOUL, P. Le corps. Paris: Flamarion, 2002.

MACHAD0, R. Nietzsche e a verdade. Rio de Janeiro: Rocco, 1985.

Deleuze e a filosofia. Rio de Janeiro: Graal, 1990.

MERLEAU PONTY, M. 0 olho e o espírito - A dúvida de Cézanne. São Paulo: Abril, 1979. (Col. Os pensadores).

SANTOS, B. de S. Um discurso sobre as ciências. São Paulo: Cortez, 2004.

WILLIANS, R. Palavras-chave: um vocabulário de cultura e sociedade. São Paulo: Boitempo, 2007.

Recebido em 12.02.09

Aprovado em 03.11.09

Francisco Romão Ferreira é graduado em Ciências Sociais pela Universidade do Estado do Rio de Janeiro, mestre em História e Crítica da Arte pela Escola de Belas Artes (UFRJ) e doutor em Ciências pela Escola Nacional de Saúde Pública, Fundação Oswaldo Cruz. 